\title{
Potential Benefits of Enterprise Architecture Management in the Digital Transformation Process
}

\author{
Ralf Härting $^{1 *}$, Christopher Reichstein ${ }^{2}$, Kurt Sandkuhl ${ }^{3}$, \\ Nathalie Hoppe ${ }^{1}$, and Hakan Yesilay ${ }^{1}$ \\ ${ }^{1}$ Aalen University of Applied Sciences, Aalen, Germany \\ ${ }^{2}$ Baden-Wuerttemberg Cooperative State University, Heidenheim, Germany \\ ${ }^{3}$ University of Rostock, Albert-Einstein-Str. 22, 18059 Rostock, Germany \\ Ralf.Haerting@hs-aalen.de, Christopher.Reichstein@dhbw-heidenheim.de, \\ kurt.sandkuhl@uni-rostock.de, Nathalie.Hoppe@kmu-aalen.de, \\ Hakan.Yesilay@kmu-aalen.de
}

\begin{abstract}
Digital transformation has an increasing influence on business processes and new business models. A successful digital transformation in enterprises requires a holistic IT infrastructure in order to meet changing business requirements. Enterprises face the challenge of combining business and IT to benefit from existing technological attainments in the digital age. As Enterprise Architecture Management (EAM) is supposed to support companies' transformation processes, it has consequently moved into the focus of large companies and small and medium-sized enterprises. Previous studies have considered the benefits of EAM taking not into account factors regarding the digital transformation process. The present study is therefore intended to close this gap. This article builds on a conceptual model based on a qualitative design with case studies. It presents a quantitative study that investigates the empirical relation between several indicators and the dependent variable "Benefits of EAM" in the digital transformation process. The results show that the indicators "IT Landscape", "Internal Business" and "EAM Establishment" positively and significantly influence the benefits of EAM in the digital transformation process.

Keywords: EAM, Enterprise Architecture, Enterprise Architecture Management, Influencing Factors, Benefit of EAM, Digital Transformation, Digital Transformation Process.
\end{abstract}

\section{Introduction}

Nowadays, companies are expected to be highly flexible and adaptable to remain competitive in an increasing globalized market [1]. Companies should therefore continuously be able to adapt

\footnotetext{
* Corresponding author
}

(C) 2020 Ralf Härting, Christopher Reichstein, Kurt Sandkuhl, Nathalie Hoppe, and Hakan Yesilay. This is an open access article licensed under the Creative Commons Attribution License (http://creativecommons.org/licenses/by/4.0).

Reference: R. Härting, Ch. Reichstein, K. Sandkuhl, N. Hoppe, and H. Yesilay, "Potential Benefits of Enterprise Architecture Management in the Digital Transformation Process," Complex Systems Informatics and Modeling Quarterly, CSIMQ, no. 24, pp. 49-60, 2020. Available: https://doi.org/10.7250/csimq.2020-24.04

Additional information. Author ORCID iD: Ch. Reichstein - https://orcid.org/0000-0003-2409-7268 and K. Sandkuhl https://orcid.org/0000-0002-7431-8412. PII S225599222000141X. Received: 15 September 2020. Accepted: 22 October 2020. Available online: 31 October 2020. 
processes and structures to changing conditions [2]. Digitalization is a key driver of transformation processes and of great relevance to companies [3]. In general, digitalization includes intelligent business processes and the use of efficient and new technology concepts such as Big Data, Cloud and Mobile Computing or Internet of Things [4]. As digital transformation can be considered the currently dominating type of business transformation, IT components play an essential role. Thereby, IT acts as a technology enabler and strategic driver for digitalization [5].

However, digital transformation is not limited to technology components. It has an increasing influence on business structures, new business models [6] and is able to change the way how companies interact and compete [7]. In order to fully benefit from the potential of digital transformation, companies need to adapt to digital technologies [6].

Enterprise Architecture Management (EAM) is expected to support companies' transformation processes and its related changes [7]. It contains management activities within a company to implement, maintain or develop an enterprise architecture (EA). In order to ensure an optimal handling of the different architectural layers of an EA, EAM comprises all necessary processes, methods and responsibilities [8]. There are various EAM frameworks, e.g. TOGAF and COBIT. The following research design is focusing on EAM in general and not on a single framework as in [1]. It was recognized that only a continuous and comprehensive management of EA can ensure the sustainability, flexibility and strategic alignment of the company's IT environment. Since the 1990s, EA has evolved into a discipline. With practical experience in implementing EA concepts, companies have increasingly incorporated EAM and its success factors. Existing information systems were constantly being changed and adapted which led to an increasing complexity of the systems. As a result, adapting to the changing business environment has become a constant challenge [9]. Because of these challenges, EA is a crucial part of today's information management and can be seen as a holistic and integrated approach [10]. It can meet various information needs of different interest groups and provides appropriate decision-making aids [11].

EAM has many benefits. Regarding digitalization, a more effective transformation process and a reduced complexity of IT are the most relevant benefits. Generally, the benefits of EAM can be defined as individual observed benefits of enterprise architecture management in companies from the perspective of EAM experts [6], [12].

Previous studies have shown that there are various important impact factors that influence the benefits of EAM [8], [13]-[16]. Such studies as [17], [18] have examined how EAM can contribute to strategic change processes or support the achievement of corporate goals. However, most of these studies are mainly focusing on business transformation [9] and the impact of digitalized products on EAM [19], but do not consider the impact of EAM within the digital transformation process. As various industries such as manufacturing and services are already taking advantage of digital transformation [20], additional impact factors which have not been considered yet, can be found.

The main goal of this work was to conduct an empirical quantitative study that examines the benefits of EAM in the digital transformation process. The work continues previous research and builds upon a conceptual model originating from a qualitative study by Reichstein et al. [1]. It adds additional factors to the previous work and their impact on the benefits of EAM is considered and we address the validation of the conceptual model from [1]. For this purpose, a statistical verification of the hypotheses was carried out.

The article proceeds as follows. In Section 2, the research design is introduced by examining the basis of this quantitative study. Section 3 deals with the research method and therefore explains the approach in detail. Section 4 includes the revised research model and the adjustments that have been made based on a literature review. After that, the results are analyzed and interpreted in Section 5, followed by a discussion in Section 6. Finally, Section 7 provides a short summary and outlook for further investigations. 


\section{Research Design}

The present quantitative research approach is based on a qualitative study published in 2019 by Reichstein et al. [1] which examines how companies can benefit from EAM in the digital transformation process. With the help of an extended literature analysis, Reichstein et al. were able to create an empirical research model which is depicted in Figure 1. The research model includes five determinants containing 22 indicators and two moderating effects [1].

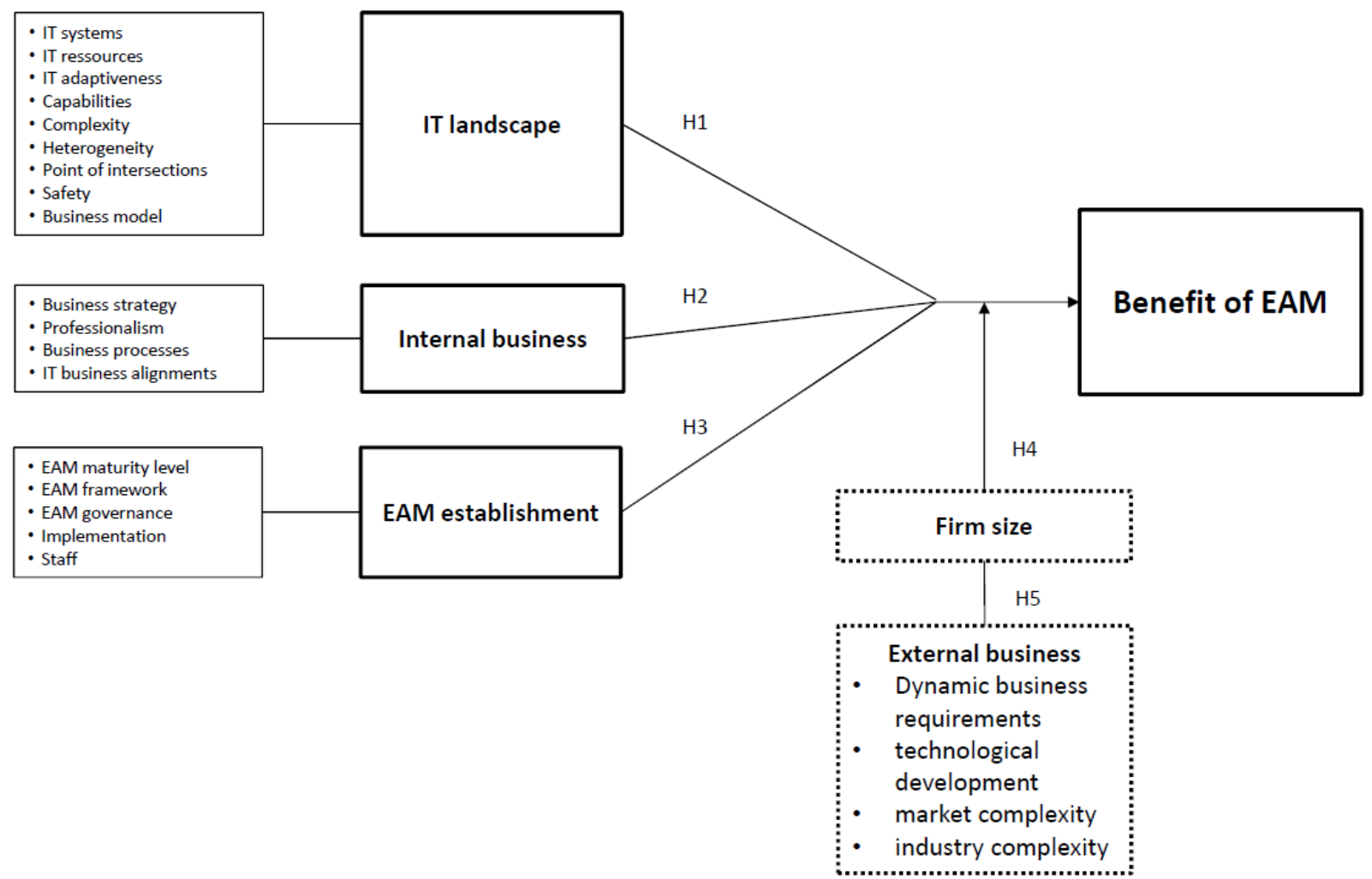

Figure 1. Research Model according to Reichstein et al. 2019 [1]

Based on the determinants, Reichstein et al. formulated the following five hypotheses [1]:

H1: A well-organized IT landscape positively influences the benefits of EAM.

H2: A well-structured internal business positively influences the benefits of EAM.

H3: A high level of EAM establishment positively influences the benefits of EAM.

H4: Firm size affects the influences regarding the benefit of EAM.

H5: External business affects the influences regarding the benefit of EAM.

Taking [1] as a basis, the first task was an empirical review of its research approach. Regarding the results of the study, the three constructs "IT landscape", "Internal business" and "EAM establishment" do have a direct influence on the benefits of EAM, while the two constructs "Firm size" and "External business" only influence the causal relationships listed in the hypotheses $\mathrm{H} 1$ to $\mathrm{H} 3$. Thus, the qualitative study [1] contained some limitations regarding these constructs. Additionally, it included only three case studies in industrial digital transformation. Therefore, in this study, more companies of different sectors and sizes were addressed. Also, the 
qualitative research model had limitations towards the scope of references. For this reason, additional literature was considered.

\section{$3 \quad$ Research Method}

Literature analysis. The existing model [1] was subjected to a review in general. The purpose of the literature analysis was to prove whether there are some additional impact factors (indicators) which can be implemented into the existing model. Another essential point was the operationalization of the constructs, primarily to check the classification and unambiguous meaning of indicators. The literature research focused on articles which were not covered by the qualitative study done before.

The analysis examined current literature up to the year 2019. The following keywords were used for finding suitable literature: "EAM", "Enterprise Architecture", "Enterprise Architecture Management", "benefit EAM", "impact factors EAM", "EAM digitalization" and "Enterprise Architecture Management digitalization". Databases SpringerLink, AISel, Web of Knowledge, EbscoHost, IEEEexplore, Science Direct and Google Scholar were examined. Because of the high amount of information about EAM, the results had to be limited. Therefore, the search items "Business Environment", "IT Landscape", "Internal Business", "EAM Establishment" were added to the above-mentioned keywords. As a result, ten articles from different journals have been identified. In the next step, the journals were examined to meet the quality criteria of VHB-Jourqual3 [21]. This means that the identified articles should have a minimum ranking of "C".

Articles that did not provide new insights for the existing model and did not meet the minimum ranking of " $C$ " were sorted out. Therefore, the number of articles could be reduced from 10 to 3. Table 1 shows an overview of the used articles: the reference, a short summary, the new indicator, the ranking of the journal according to the VHB-Jourqual and the 5 determinants.

Table 1. Summary of Literature Review for finding new indicators

\begin{tabular}{|c|c|c|c|c|c|c|c|c|}
\hline Author & Summary & 莺 & 告 & 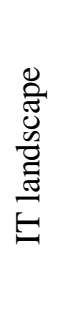 & 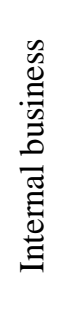 & 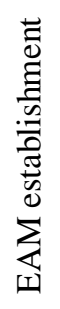 & 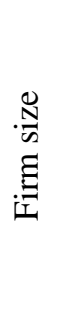 & 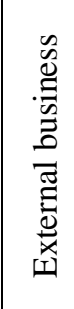 \\
\hline [22] & $\begin{array}{l}\text { Some studies have explained the important } \\
\text { role of stakeholders in the effective execution } \\
\text { and access of EA. }\end{array}$ & Stakeholder & $\mathrm{C}$ & & & & & X \\
\hline [9] & $\begin{array}{l}\text { The research, based on empirical data, shows } \\
\text { that organizational culture significantly } \\
\text { influences the way enterprise architecture } \\
\text { principles' (EAP) grounding, management, } \\
\text { and EAP guidance affect EA consistency and } \\
\text { EAM utility. }\end{array}$ & $\begin{array}{l}\text { Organizational } \\
\text { culture }\end{array}$ & $\mathrm{C}$ & & & $X$ & & \\
\hline [23] & $\begin{array}{l}\text { Enterprise architecture management is the } \\
\text { continuous practice of describing and } \\
\text { updating the EA in order to understand } \\
\text { complexity and manage change }\end{array}$ & $\begin{array}{l}\text { Continuous } \\
\text { development } \\
\text { of EAM }\end{array}$ & $\mathrm{C}$ & & & $X$ & & \\
\hline
\end{tabular}

Data collection. The next step was the determination of the survey participants. The target group included people with management functions or executive positions in IT departments. Department and division managers, team leaders and IT responsible persons were taken into account. Addressing companies, the focus was on different industries to gain wide-ranging 
results. The survey participants were contacted through various communication channels and platforms.

The focus was especially on business platforms and on contacting companies via e-mail. Before starting the survey, it was transmitted to the survey tool LimeSurvey. All items (also new items from the literature review) have been included in the questionnaire. Some of the questions are presented in Section 5. Furthermore, a pre-test was necessary to investigate whether all questions are precise and understandable. The suggestions for improvements were implemented and after that the survey could finally be conducted. The implementation period was about one month.

Data analysis. In order to analyze the relationship between the impact factors (indicators) and the benefit of EAM the structural equation modeling approach was used. The Structural Equation Model is a useful tool to test hypotheses about relationships between variables. Structural Equation Modeling (SEM) is a second-generation multivariate data analysis method which is often used in research because it can test theoretically supported linear and additive causal models. There are two submodels in a structural equation model: the inner model and the outer model. The inner model is also known as the structural model and the outer model is known as the measurement model. The inner model specifies the relationships between the independent and dependent latent variables, whereas the outer model is specifying the relationships between the latent variables and their observed indicators. There are different SEM software packages like AMOS, EQS, LISREL or SmartPLS available. The authors chose SmartPLS due to its robustness and data requirements. SmartPLS is a statistics software for Partial Least Squares Structural Equation Modeling (PLS-SEM) [24].

Only data of completed questionnaires were subsequently evaluated. SmartPLS was used to examine the survey results for correlations between the dependent and independent variables. For this purpose, the path coefficient and the p-value were used.

\section{$4 \quad$ Revised Research Model}

The basis of the revised research model (see Figure 2) is the existing research model [1] described in Section 2. The revised research model consists of five determinants: "IT landscape", "Internal business", "EAM establishment", "Firm size" and "External business" including 21 indicators and two moderating effects "Firm size" and "External business".

In view of this structural equation model the reflective measurement scale is used. Thus, 21 single items were derived from the corresponding constructs. To sum up the whole revised research model: the benefit of EAM is impacted by three direct influencing variables and through two moderating effects, which can strengthen or weaken the effects of the three direct influencing variables.

Compared to the existing research model (see Figure 1), the number of determinants has remained the same. The main difference between the revised research model and the existing research model is a correction of the arrangement of the moderating effects. The moderating effects "Firm size" and "External business" are effects, which are independent of each other, hence they should be considered separately. The common line of the two moderating effects was divided into two separate lines.

The following allocations and adjustments within the revised research model have also been made:

- The number of indicators compared to the existing research model decreased from 22 to 21 .

- Within the general review of Reichstein et al. [1], the following items were taken out from the model due to content overlapping with other indicators: IT systems, Point of intersections, Dynamic business requirements and Industry complexity.

- According to the literature analysis (see Table 1), the following items were added to the model: Continuous development of EAM [23], Organizational culture [9] and Stakeholder involvement [22]. 


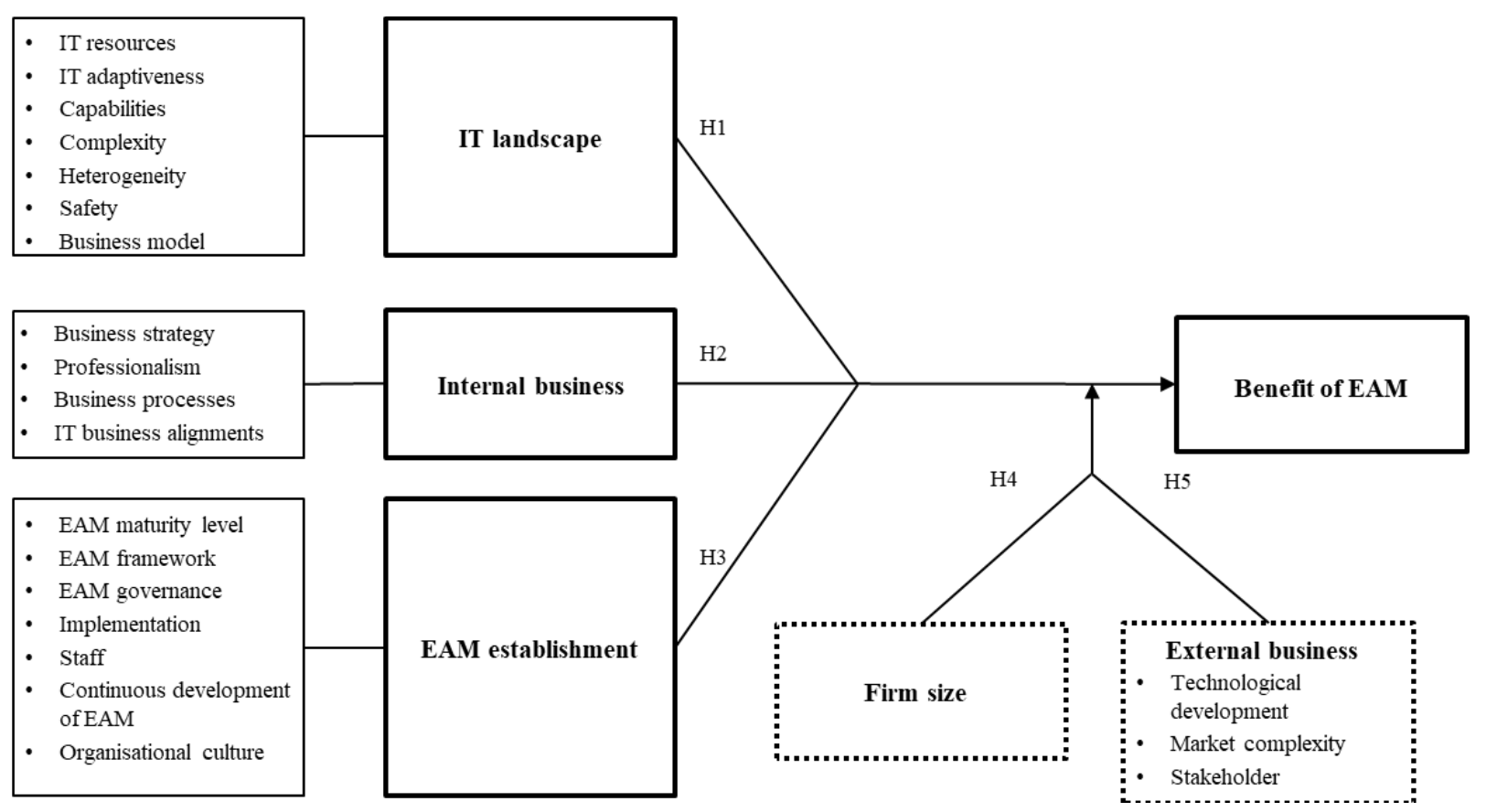

Figure 2. Revised Research Model based on Reichstein et al. 2019 [1]

\section{$5 \quad$ Results}

A total of 173 respondents took part in the online survey. Due to cancelled surveys or incomplete information, the adjusted sample is $\mathrm{N}=115$. The sample consists of 40 (35\%) female and 75 $(65 \%)$ male respondents. At the beginning of the survey, the respondents were asked whether their company uses digitalization approaches and, if yes, which ones they use. Most of the survey participants used new approaches, especially Big Data (46\%), Cloud Computing (45\%), Mobile Computing (37\%) and Evaluation of customer behavior (33\%) depicted in the diagram below (see Figure 3).

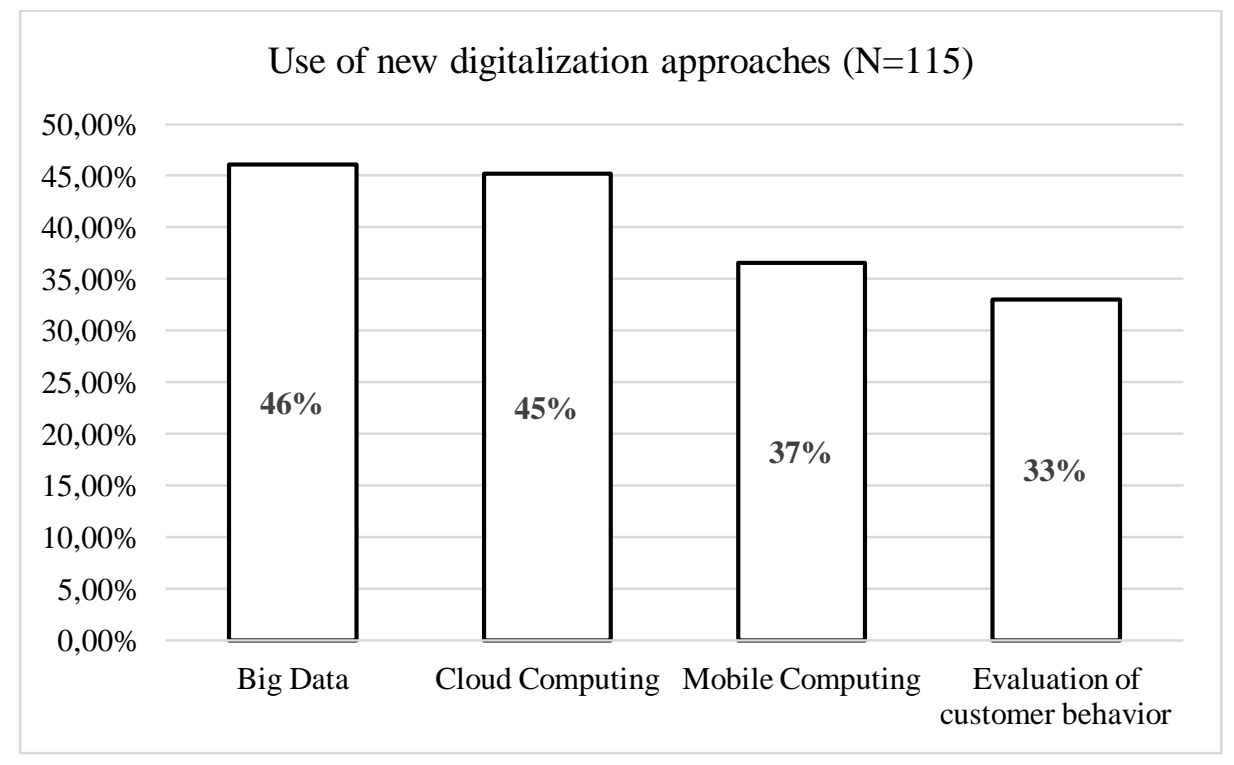

Figure 3. Use of new digitalization approaches based on survey results

Another remarkable finding results from the question whether the participants use EAM in their companies. The study revealed that half of the participants $(50 \%)$ did not used EAM in their 
companies. The next question was about figuring out how many years the participants had been using EAM in their companies. There were participants who answered that they had been using EAM for over six years (9\%). The majority of companies $(26 \%)$ with implemented EAM indicated that they had been using it for one to two years. Most participants worked in the Information and Communication/IT sector (17\%). In the second place, there were Trade/Transport (15\%) and Manufacturing Industry/Production (15\%) sectors. Next, the participants were asked how many employees their company had. While 3\% did not want to give any information, 55\% of the participants stated that their company had more than 250 employees. Furthermore, 23\% indicated the option "50 to 250 employees".

Apart from that, most of the respondents (40\%) worked in companies with an annual turnover of over EUR 40 million; 18\% of the participants worked in companies that earned less than EUR 12 million annually; and 16\% worked in companies that earned between EUR 12 and 40 million annually. The participants were also asked about their job function. With $26 \%$, the majority were team leaders followed by "others" (23\%) and "IT-Manager" (22\%). Regarding professional experience, 33 participants $(29 \%)$ in total had professional experience of more than ten years.

The results of the structural equation model are shown in Figure 4:

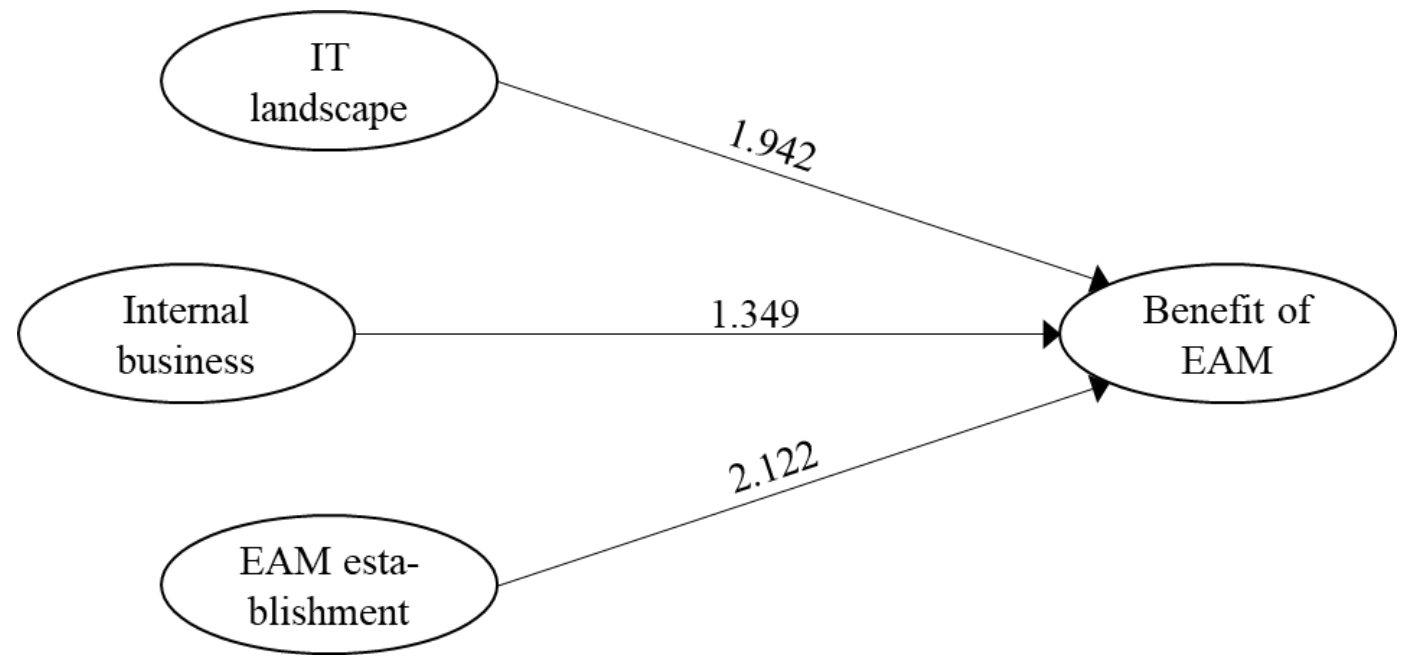

Figure 4. Structural equation model with coefficients of the t-statistics

With the reference to Hypothesis 1 (A well-organized IT landscape positively influences the benefits of EAM), the analysis using SEM shows a positive significant influence with a p-value of 0.026 . Furthermore, the path coefficient is 0.310 which represents a weak and positive significance. Since a one-sided significance test was conducted with a significance level of $10 \%$, the critical value is 1.65 . The t-value is 1.942 and thus it exceeds the critical value. Therefore, a statistical significance can be assumed. Consequently, the hypothesis can be confirmed. Thus, it can be said that the benefits of EAM increase with a well-organized IT landscape.

Regarding Hypothesis 2 (A well-structured internal business positively influences the benefits of EAM), the SEM analysis shows a positive significant p-value of 0.089 at the significance level of $10 \%$. The path coefficient is 0.149 and the t-value is 1.349 . Consequently, a wellstructured internal business has a positive influence on the benefits of EAM.

Regarding Hypothesis 3 (A high level of EAM establishment positively influences the benefits of EAM), the analysis using SEM shows a path coefficient of 0.318 , and a p-value of 0.017 which is a weak positive and significant influence. Additionally, the t-value is 2.122 which indicates a statistical significance. Consequently, the EAM establishment has a positive influence on the benefits of EAM.

In order to analyze the moderating effect firm size, the aggregated data was divided into two groups (Figure 5): small and medium-sized enterprises (SMEs) with a turnover of less than EUR 
40 million and large enterprises with a turnover of more than EUR 40 million. A table with all values from the analysis of the structural equation modeling can be found in the appendix.

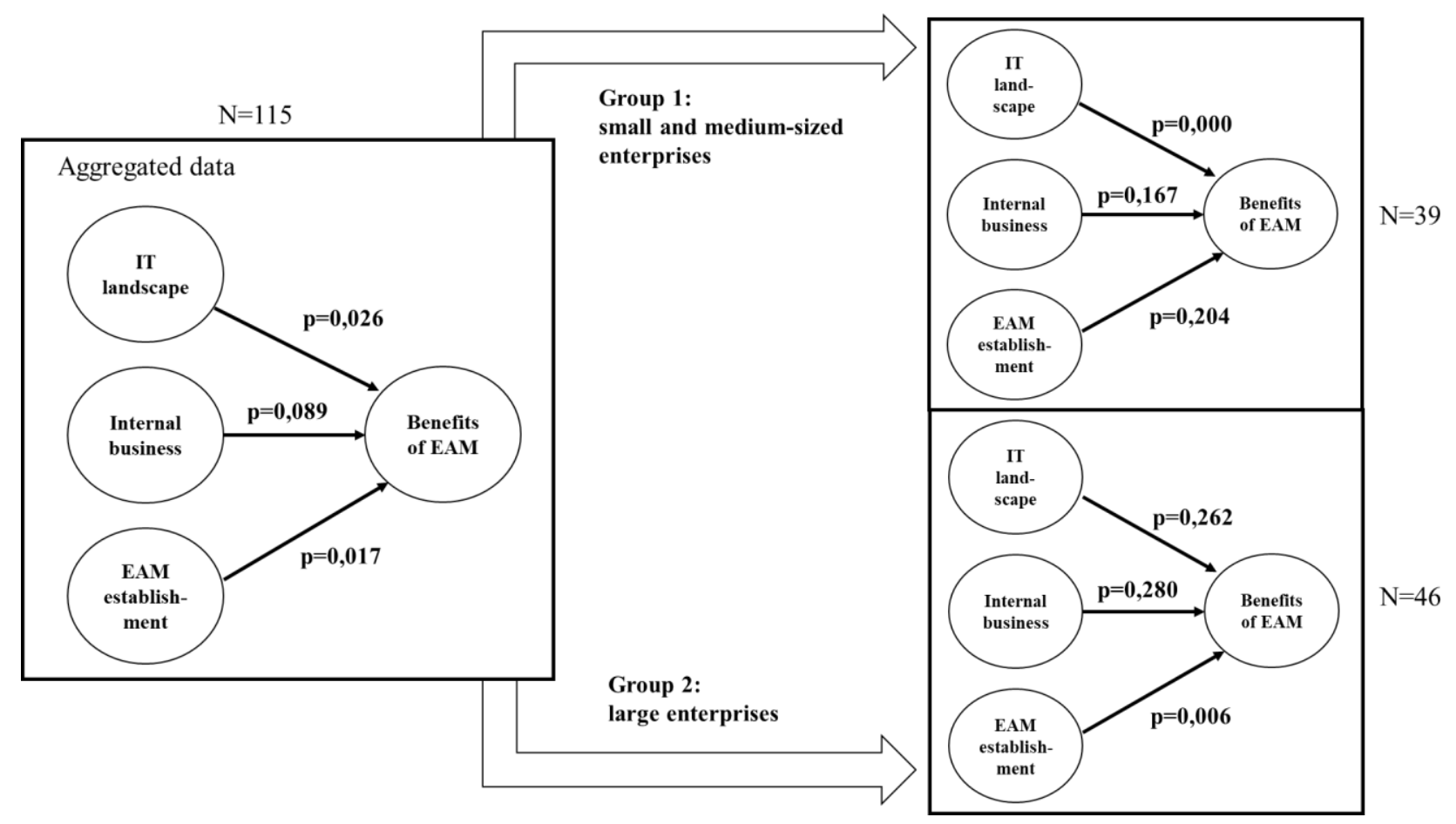

Figure 5. Moderating effect firm size clustered into two groups

For each clustered group only one of three hypotheses can be confirmed. While for small SMEs IT landscape is the significant factor, for large enterprises the EAM establishment is significant.

However, the p-values of the two clustered groups are much more significant than in the case of the aggregated data. Due to clustering, the sample size for SME-group is 39 and the sample size for the large enterprise group is 46.

\section{Discussion}

To summarize, all three main hypotheses are accepted at the significance level of $10 \%$.

Factors such as the improved use of IT resources, the adaptation of IT systems to relevant processes and the alignment of IT to the business model can contribute to a well-organized IT landscape. Focusing on the benefits of EAM regarding digital transformation we can derive that the growing complexity of IT can be reduced by EAM. Apart from a well-organized IT landscape, internal business processes can have a positive impact on the benefits of EAM in the digital transformation process. In this context, the optimal implementation of the business strategy, the increased professionalism of the company, the optimization of the business processes, and an improved IT connection to other company divisions are the influences on the benefits of EAM. Moreover, it can be assumed that a clearly defined EAM framework and the integration of the organizational culture into EAM are decisive factors for a successful establishment of EAM. The results of all items can be found in the appendix.

According to the results of the moderating effect "Firm size", it could be suggested that large companies should focus more on EAM establishment while SME should focus more on the IT landscape. Larger companies must take much more issues into account than SME when establishing EAM due to the organizational and process complexity. For small and mediumsized businesses, the IT landscape may play a greater role referred to IT resources and IT capabilities. To draw a conclusion, the sample size per group should be at least 100 . 


\section{Conclusion}

Building on the qualitative study of Reichstein et al. [1], the quantitative research approach allowed a further empirical investigation on the benefits of EAM in the digital transformation process. According to an extended literature review, the research model [1] could be complemented by additional influencing factors (indicators). At the same time, items that overlapped in content were deleted. The results show that the determinants "IT landscape", "Internal business" and "EAM establishment" positively and significantly influence the benefits of EAM in the digital transformation process.

Beside the main factors, the moderating effect firm size enabled to examine differences between SMEs and large companies. One of three hypotheses could be accepted. However, the p-values of the two clustered groups were much more significant than in the case of the aggregated data. Due to organizational complexity, it could be useful for large companies to focus on EAM establishment including cross-divisional implementation and the integration of the organizational culture while SMEs should rather focus on the IT landscape which includes IT capabilities.

This work illustrates that EAM cannot be seen as a task which is separated from other departments and processes of a company. In fact, it has to be seen as a holistic approach that is preferably linked to the strategy and business model.

For companies that consider implementing EAM, it can be recommended that organizations should not hesitate in aligning the IT processes according to EAM. As a result, companies would be able to transparently communicate the importance of EAM. This can also lead to an avoidance of stakeholder resistance to EAM [25].

This article is subject to some limitations. The survey focuses on German-speaking participants, so there was no integration of international experts. Therefore, it could be tested globally or throughout Europe. This enables to investigate the differences in various regions with different working cultures.

By increasing the sample size, further investigations can be carried out. It would be possible to conduct the study sector-specifically or according to company size creating a comparison within sectors or between SMEs and large companies. The subject of future research may be the consideration of different results regarding the influencing factor "Firm size". Furthermore, the moderating effect "External business" may also be examined.

With regard to the future, EAM will become more and more important in the course of the digital transformation process. Due to the increasing complexity and dynamic changes in market conditions, growth-oriented companies will not be able to avoid the implementation of EAM. Due to the positive perception of EAM based on this study, it can also be noted that a large number of companies has already implemented EAM.

In order to keep up with the new developments in companies and to cope with the increasing speed of future processes, EAM has to be extended by using faster and more agile methods like Scrum or Design Thinking. In a complex environment, characterized by rapid and frequent changes, the usage of methods like Scrum causes for EAM projects a wide-ranging reduction of implementation costs due to increased reaction speed, improved teamwork and enhanced trust [12].

\section{Acknowledgement}

Our research has been supported by Adelina Henneberg, Katharina Ignatev, Tabita Prosenbauer and Felix Häfner. We would like to thank you all. 


\section{References}

[1] C. Reichstein, R.-C. Härting, and K. Sandkuhl, "How companies can benefit from Enterprise Architecture Management - An Extended Research Model," Enterprise Modelling and Information Systems Architectures, vol. 14, no. 6, pp. 1-22, 2019. Available: https://doi.org/10.18417/emisa.14.6

[2] M. Mykhashchuk, S. Buckl, T. Dierl, and C. M. Schweda, "Charting the landscape of enterprise architecture management - An extensive literature analysis," 10th Internationale Tagung Wirtschaftsinformatik 2011, Zürich, Switzerland, 2011.

[3] E. Henriette, M. Feki, and I. Boughzala, "Digital Transformation Challenges," MCIS 2016 Proceedings, pp. 1-7, 2017.

[4] C. Reichstein, R.-C. Härting, and P. Neumaier, "Understanding the Potential Value of Digitization for Business - Quantitative Research Results of European Experts," KES International Symposium on Agent and MultiAgent Systems: Technologies and Applications, Springer, pp. 287-298, 2018. Available: https://doi.org/10.1007/978-3-319-92031-3_29

[5] A. Zimmermann, R. Schmidt, K. Sandkuhl, D. Jugel, J. Bogner, and M. Möhring, "Evolution of Enterprise Architecture for Digital Transformation," 2018 IEEE $22^{\text {nd }}$ International Enterprise Distributed Object Computing Workshop, Stockholm, Sweden, 2018. Available: https://doi.org/10.1109/EDOCW.2018.00023

[6] R.-C. Härting, C. Reichstein, and K. Sandkuhl, "Determinants to Benefit from Enterprise Architecture Management - A Research Model," International Conference on Business Information Systems, Springer, pp. 101-111, 2018. Available: https://doi.org/10.1007/978-3-030-04849-5_9

[7] M. Hafsi and S. Assar, "Managing Strategy in Digital Transformation Context: An Exploratory Analysis of Enterprise Architecture Management Support," 2019 IEEE $21^{\text {st }}$ Conference on Business Informatics (CBI), Moscow, Russia, 2019.

[8] M. Lange, J. Mendling, and J. Recker, "An empirical analysis of the factors and measures of Enterprise Architecture Management success,” European Journal of Information Systems, vol. 25, no. 5, pp. 411-431, 2016. Available: https://doi.org/10.1057/ejis.2014.39

[9] R. Winter, C. Legner, and K. Fischbach, "Introduction to the special issue on enterprise architecture management," Information Systems and e-Business Management, vol. 12, pp. 1-4, 2013. Available: https://doi.org/10.1007/s10257-013-0221-4

[10] S. Lauvrak, V. M. Michaelsen, and D. H. Olsen, "Benefits and challenges with Enterprise Architecture: a case study of the Norwegian Labour and Welfare Administration," Bibsys Open Journal Systems, Paper presented at NOKOBIT 2017, Oslo, 27-29 Nov. NOKOBIT, vol. 25, no. 1, 2017.

[11] I. Hanschke, Enterprise Architecture Management - einfach und effektiv. Ein praktischer Leitfaden für die Einführung von EAM, Hanser Books, München, 2016 (in German). Available: https://doi.org/10.3139/9783446449350.fm

[12] R. Kaim, R. Härting, and C. Reichstein, "Benefits of Agile Project Management in an Environment of Increasing Complexity - A Transaction Cost Analysis," Conference Proceeding KES-IDT, Springer, pp. 195-204, 2019. Available: https://doi.org/10.1007/978-981-13-8303-8_17

[13] H. Cooper, Synthesizing Research: A Guide for Literature Reviews, 2nd ed. Applied Social Research Methods. SAGE Publications, 1998.

[14] E. Niemi, T. Ylimäki, and N. Hämäläinen, "Evaluation of enterprise and software architectures: critical issues, metrics and practices: [AISA Project 2005-2008]," University of Jyväskylä, Information Technology Research Institute, 2008.

[15] C. Schmidt and P. Buxmann, "Outcomes and success factors of enterprise IT architecture management: empirical insight from the international financial services industry," European Journal of Information Systems, vol. 20, no. 2, pp. 168-185, 2011. Available: https://doi.org/10.1057/ejis.2010.68

[16] R. Schmidt, M. Möhring, R.-C. Härting, C. Reichstein, A. Zimmermann, and S. Luceri, "Benefits of enterprise architecture management - insights from European experts," IFIP Working Conference on The Practice of Enterprise Modelling, Springer, pp. 223-236, 2015. Available: https://doi.org/10.1007/978-3-319-25897-3_15

[17] F. Radeke, “Toward Understanding Enterprise Architecture Management's Role in Strategic Change: Antecedents, Processes, Outcomes," Wirtschaftsinformatik Proceedings, 2011.

[18] R. Foorthuis, M. van Steenbergen, N. Mushkudiani, W. Bruls, S. Brinkkemper, and R. Bos, "On Course, but Not There yet: Enterprise Architecture Conformance and Benefits in Systems Development," ICIS 2010 Proceedings, 2010. 
[19] K. Sandkuhl, M. Wißotzki, R. Schmidt, and A. Zimmermann, "On the Effect of Digitalization of Products and Services on Enterprise Architectures," Information Systems Development: Information Systems Beyond 2020 (ISD2019 Proceedings), 2019.

[20] R. Härting, C. Reichstein, and P. Jozinovic, "The Potential Value of Digitization for Business - Insights from German-speaking Experts," Informatik, 2017.

[21] Verband der Hochschullehrer für Betriebswirtschaft e.V.: Liste der Fachzeitschriften in VHB-JOURQUAL3 (in German). Available: https://vhbonline.org/vhb4you/vhb-jourqual/vhb-jourqual-3/gesamtliste. Accessed on May 8, 2020.

[22] H. Al-Kharusi, S. Miskon, and M. Bahari, "Factors influencing the engagement between enterprise architects and stakeholders in enterprise architecture development," PACIS 2016 Proceedings, 262, pp. 1-12, 2016.

[23] J. Lapalme, A. Gerber, A. Van der Merwe, J. Zachman, M. De Vries, and K. Hinkelmann, "Exploring the future of enterprise architecture: A Zachman perspective,” Computers in Industry, vol. 79, pp. 103-113, 2015. Available: https://doi.org/10.1016/j.compind.2015.06.010

[24] K. K. Wong, "Partial least squares structural equation modeling (PLS-SEM) techniques using SmartPLS," Marketing Bulletin, vol. 24, no. 1, pp. 1-32, 2013.

[25] J. Löhe and C. Legner, "Overcoming implementation challenges in enterprise architecture management: a design theory for architecture-driven IT Management (ADRIMA)," Information Systems and e-Business Management, vol. 12, pp. 101-137, 2014. Available: https://doi.org/10.1007/s10257-012-0211-y 


\section{Appendix}

Results of the measurement and structural equation model

\begin{tabular}{|l|c|c|c|c|c|c|c|}
\hline determinants & $\begin{array}{c}\text { Original Sample } \\
\text { / Outer loadings }\end{array}$ & $\begin{array}{c}\text { Standard } \\
\text { Deviation }\end{array}$ & $\begin{array}{c}\text { T- } \\
\text { Statistics }\end{array}$ & $\begin{array}{c}\text { P- } \\
\text { Value }\end{array}$ & AVE & $\begin{array}{c}\text { Cronbachs } \\
\text { Alpha }\end{array}$ & $\begin{array}{c}\text { Composite } \\
\text { Reliability }\end{array}$ \\
\hline IT landscape & $\mathbf{0 . 3 1 0}$ & $\mathbf{0 . 1 5 9}$ & $\mathbf{1 . 9 4 2}$ & $\mathbf{0 . 0 2 6}$ & $\mathbf{0 . 5 7 6}$ & $\mathbf{0 . 8 9 5}$ & $\mathbf{0 . 9 1 5}$ \\
\hline IT resources & 0.801 & 0.039 & & & & & \\
\hline IT adaptiveness & 0.825 & 0.045 & & & & & \\
\hline Capabilities & 0.765 & 0.052 & & & & & \\
\hline Complexity & 0.717 & 0.052 & & & & & \\
\hline Heterogeneity & 0.707 & 0.052 & & & & & \\
\hline Safety & 0.690 & 0.054 & & & & & \\
\hline Business model & 0.801 & 0.045 & & & & & $\mathbf{0 . 8 6 8}$ \\
\hline Internal business & $\mathbf{0 . 1 4 9}$ & $\mathbf{0 . 1 1 0}$ & $\mathbf{1 . 3 4 9}$ & $\mathbf{0 . 0 8 9}$ & $\mathbf{0 . 5 6 9}$ & $\mathbf{0 . 8 1 0}$ & \\
\hline Business strategy & 0.694 & 0.071 & & & & & \\
\hline Professionalism & 0.813 & 0.036 & & & & & \\
\hline Business processes & 0.762 & 0.055 & & & & & \\
\hline $\begin{array}{l}\text { IT business } \\
\text { alignments }\end{array}$ & 0.714 & 0.063 & & & & & \\
\hline EAM establishment & $\mathbf{0 . 3 1 8}$ & $\mathbf{0 . 1 5 0}$ & $\mathbf{2 . 1 2 2}$ & $\mathbf{0 . 0 1 7}$ & $\mathbf{0 . 5 6 3}$ & $\mathbf{0 . 8 8 8}$ & $\mathbf{0 . 9 1 1}$ \\
\hline EAM maturity level & 0.712 & 0.052 & & & & & \\
\hline EAM framework & 0.725 & 0.070 & & & & & \\
\hline EAM governance & 0.799 & 0.038 & & & & & \\
\hline Implementation & 0.729 & 0.054 & & & & & \\
\hline Staff & 0.790 & 0.043 & & & & & \\
\hline $\begin{array}{l}\text { Continuous develop- } \\
\text { ment of EAM }\end{array}$ & 0.849 & 0.031 & & & & & \\
\hline $\begin{array}{l}\text { Organizational } \\
\text { culture }\end{array}$ & 0.663 & 0.065 & & & & & \\
\hline
\end{tabular}

